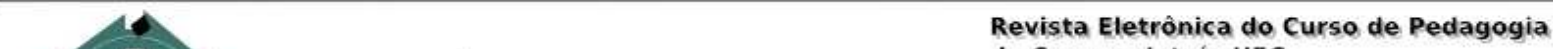

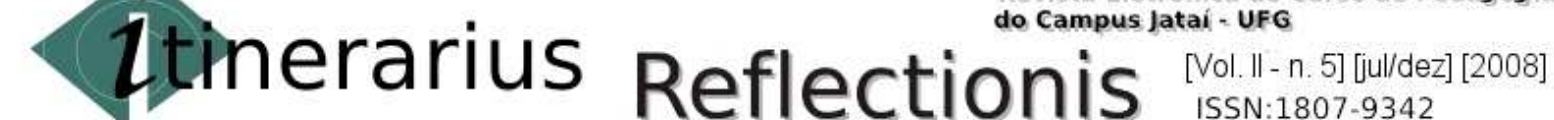

\section{A PRODUÇÃO CIENTÍFICA NA FORMAÇÃO DOS ALUNOS DO CURSO DE EDUCAÇÃO FÍSICA DO CAJ/UFG}

\author{
Renata Machado de Assis ${ }^{*}$ \\ Naiêssa Araújo Bonifácio ${ }^{* *}$
}

\begin{abstract}
RESUMO: Este artigo visa divulgar uma pesquisa realizada no curso de Educação Física do Campus Jataí da Universidade Federal de Goiás (CAJ/UFG), que teve como objetivo investigar como se encontrava a produção científica dos 111 alunos matriculados regularmente no ano de 2006. A metodologia adotada foi pesquisa qualitativa-descritiva e os instrumentos de coleta de dados foram: questionário, entrevista e análise documental. Foi possível perceber, a partir das informações encontradas na realidade investigada, que a produção científica por parte dos acadêmicos de Educação Física ainda é restrita e origina-se, predominantemente, das experiências em projetos de extensão, seguidas pelas situações de pesquisa e, em grau que podemos considerar insuficiente, pelo ensino, considerando-se a quantidade de disciplinas cursadas. A justificativa para esta situação, a partir da opinião dos sujeitos, é de que há pouco incentivo por parte dos professores, existe a falta de interesse dos próprios alunos, falta de tempo e precariedade de estrutura física da faculdade e poucas bolsas disponíveis para os projetos. A produção científica na licenciatura é um ponto que requer especial atenção, pois pode contribuir em grande escala na formação do professor pesquisador.
\end{abstract}

Palavras- chave: universidade, produção científica, formação.

ABSTRACT: This article wants to publicize a survey carried out in the course of Physical Education at Campus Jataí of the Federal University of Goiás (CAJ/UFG), which aimed to investigate how was the scientific production of the 111 students enrolled regularly in 2006 . The methodology was qualitative-descriptive and instruments for data collection were: questionnaire, interview and documentary analysis. It was possible to understand from the information found in the reality investigated, that the scientific production by students from Physical Education is still limited and the origins are, predominantly, their experience in projects of extension, followed by research situations and, in a lesser degree, teaching, considering the amount of subjects of the course. The reasons for this situation, from the participants' point of view, is the little incentive on the part of teachers, the lack of interest from students, lack of time and lack of physical structure of the university, as well as few scholarships available for projects. The scientific production in the majoring is a point that requires special attention because it can contribute on a large scale in the formation of there searcher teacher.

Key words: University, scientific production, formation

\footnotetext{
* Mestre em Educação - Docente do curso de EF/CAJ/UFG renatafef@hotmail.com

${ }^{* *}$ Professora de Educação Física, graduada no curso de EF/CAJ/UFG
} 


\section{Introdução}

Inicialmente, devemos compreender a Universidade e, para tal, devemos analisar suas funções e como estas vêm sendo executadas junto à sociedade, visto que a universidade está inserida em uma comunidade e deve atuar na realidade, formando profissionais de diversas áreas para atuarem no mercado de trabalho. Porém, esta não é a única finalidade da universidade. Entendemos que este é um processo muito mais amplo.

Segundo Vasconcelos (1999), a Universidade é um local em que se privilegia, antes de tudo, a transmissão do saber já consagrado, criadora de novos saberes, além de ser uma instituição investigadora, com estímulo à curiosidade, à ousadia e à iniciativa. Este autor considera que, inserida em uma realidade histórica, política e social, a Universidade deve atuar e intervir neste contexto.

Constituindo-se como uma instituição educacional, a universidade tem grande comprometimento pela busca do saber. Os alunos que têm a possibilidade de ingressar em um curso superior devem ter a oportunidade de enriquecer seu acervo de conhecimentos e, com isso, fundamentar o seu processo de formação.

Baseados neste princípio, os cursos de graduação em nível superior devem formar seus alunos para o exercício da profissão em um determinado campo de atuação. Esta formação deve propiciar ao aluno a capacidade de ter uma visão crítica do meio em que irá atuar, ou seja, em sua prática profissional. Além disso, quando tratamos de formação, compreendemos não só a formação para o futuro de trabalho, mas também para a vida, um crescimento como cidadão, capaz de intervir na realidade em que vive.

A esse respeito, Coêlho (1996) afirma que formação universitária não pode ser definida somente como transmissão de informações e técnicas, nem como instrução ou simples profissionalização. A formação universitária inclui e ultrapassa todas estas funções, pois se refere ao homem como um todo, capaz de compreender a natureza, a sociedade e o próprio homem. Mais do que profissionalizar, formar na universidade significa desenvolver no indivíduo a capacidade de entender e transformar a realidade na qual está inserida.

A Universidade é uma instituição educacional diferente da educação básica, por apresentar a possibilidade do desenvolvimento da pesquisa e da extensão juntamente com o ensino. Desta forma, ao ingressar na Universidade, o aluno depara-se com uma nova realidade, em relação ao que ele já vivenciou anteriormente em sua vida escolar. Por isso, é preciso despertar no acadêmico o interesse de se qualificar da melhor forma e, como parte 
imprescindível de sua formação, o discente deve participar efetivamente deste sistema, no qual ele tem liberdade de aprender, pesquisar e participar de projetos voltados para a comunidade.

Segundo Aragão et al (1999), a formação universitária deve ocorrer mediante uma proposta baseada em uma dimensão "tripartile", voltada para o desenvolvimento de ensino, pesquisa e extensão. Esta formação só é considerada completa quando o conhecimento é propiciado a partir destes três princípios. Vasconcelos (1996, p. 8) justifica que “... ensino, pesquisa e extensão representam, com igualdade de importância, o tripé que dá sustentação a qualquer universidade que se pretenda manter como tal".

Aragão et al (1999) afirmam que, apesar de algumas exceções, na maioria das universidades, neste caso especificamente nos cursos de Educação Física, os três eixos norteadores se apresentam de forma fragmentada e desarticulada. Verifica-se, desta maneira, que o ensino se encontra como um "adestramento" de ensinar por ensinar. A pesquisa limitase à simples obrigação de produzir um trabalho científico de conclusão do curso e a extensão é representada somente por estágios.

Além desta preocupação, Vasconcelos (1996) relata que, na maioria dos casos, cada universidade dá ênfase maior ou menor a um destes três campos. Deste modo, não atinge a real definição de Universidade, deixando de lado a possibilidade de interligar esses três pólos, constituindo uma instituição de ensino incompleta.

A partir da concepção de Universidade, entendida como um espaço de formação com inter-relação com a sociedade, por meio de um projeto que interliga o ensino, a pesquisa e a extensão, produzir e disseminar o conhecimento científico torna-se uma atividade que traduz toda a experiência vivenciada na Universidade, com o compromisso de transmitir o conhecimento para a sociedade. Deste modo, a pesquisa é uma aliada importante na formação de professores.

Quando não há desenvolvimento da produção científica, o conhecimento proporcionado pela Universidade limita-se ao ensino. Desta forma, a pesquisa deixa de ser usada como estratégia pedagógica durante a graduação. Fávero (1994) afirma que a produção científica nem sempre é parte integrante nos cursos de graduação. Esta situação se contrapõe à finalidade primordial da universidade e de suas unidades, a produção e socialização do conhecimento, por intermédio do ensino e da extensão.

Após discutirmos a relação entre ensino, pesquisa, extensão e a produção do conhecimento na universidade, entendemos ser de fundamental importância que se ofereça 
aos acadêmicos do curso de Educação Física uma boa formação, para que possam agir criticamente na sociedade.

\section{Nossos Objetivos}

O objetivo geral desta pesquisa foi investigar como se encontrava a produção científica dos alunos do curso de Educação Física no Campus Jataí, da Universidade Federal de Goiás no ano letivo de 2006. Na intenção de atingir este objetivo, traçamos como metas específicas: verificar se há interesse dos alunos em realizar produção científica durante o curso de Educação Física CAJ-UFG; identificar a importância da produção científica na graduação em Educação Física como parte integrante do processo de formação profissional dos alunos; e averiguar o que tem sido produzido pelos alunos no curso de Educação Física CAJ-UFG.

\section{O Caminho Percorrido}

A pesquisa desenvolvida se caracteriza como qualitativa, do tipo descritivo. Foi realizado um estudo bibliográfico e pesquisa de campo, no intuito de conseguir informações sobre o problema sobre o qual nos comprometemos investigar.

Nossa pesquisa de campo teve como sujeitos os alunos matriculados e que frequientavam regularmente o curso de Educação Física do Campus Jataí, da Universidade Federal de Goiás, durante o ano de 2006. Colaboraram com nossa pesquisa 111 alunos do curso, caracterizados como do $1^{\circ}$ período de $\mathrm{A} 1$ até $\mathrm{A} 30$, do $3^{\circ}$ período de $\mathrm{B} 1$ a $\mathrm{B} 30$, do $3^{\circ}$ ano de $\mathrm{C} 1$ a $\mathrm{C} 23$ e do $4^{\circ}$ ano de D1 a D27. ${ }^{1}$ Utilizamos estes nomes fictícios na intenção de respeitar o anonimato dos sujeitos na aplicação dos questionários, pedindo apenas a identificação daqueles alunos selecionados para a próxima etapa referente à entrevista e análise documental.

Para coletar as informações dos nossos sujeitos, utilizamos como instrumentos de pesquisa o questionário, destinado a todos os alunos do curso de Educação Física, em seguida realizamos uma entrevista semi-estruturada com aqueles que afirmaram em suas respostas possuir uma produção científica publicada, e fizemos uma análise documental das suas

\footnotetext{
${ }^{1}$ Neste ano em que ocorreu a investigação (2006), duas grades curriculares estão em vigência, a anterior no regime anual (terceiro e quarto ano), e a atual no regime semestral (primeiro e terceiro período). Neste último modo, houve entrada de turmas apenas no início do ano, por isto não existem o segundo e o quarto períodos.
} 
publicações (artigos, resumos de trabalhos, textos, etc). Os questionários foram entregues na própria sala de aula dos sujeitos, com a devida autorização do professor presente, disposto a ceder um tempo de sua aula para que os acadêmicos estruturassem as respostas.

Optamos pela entrevista semi-estruturada com os que, de acordo com Triviños (1996, p.146),"parte de certos questionamentos básicos, apoiados em teorias e hipóteses, que interessam à pesquisa, e que, em seguida, oferecem amplo campo de interrogativas, fruto de novas hipóteses do informante".

Além do questionário e da entrevista semi-estruturada, tornou-se relevante para a pesquisa fazermos uma análise documental dos trabalhos científicos que foram recolhidos dos alunos que já possuam alguma publicação. Segundo Lüdke e André (1986, p.38), “a análise documental pode se constituir numa técnica valiosa de abordagem dos dados qualitativos seja complementando as informações obtidas por outras técnicas, seja desvelando aspectos novos de um tema ou problema".

Após a coleta dos dados procedemos à análise e interpretação dos mesmos. Nesta fase do trabalho, cruzamos os dados encontrados na pesquisa de campo com o referencial teórico obtido pela pesquisa bibliográfica.

\section{A Realidade Investigada}

De posse dos dados coletados, esclarecemos os fatores que influenciam a produção científica, de acordo com a perspectiva dos sujeitos, para assim podermos conhecer o que determina alguns discentes a produzirem e outros a não produzirem cientificamente, durante a graduação.

O principal fator abordado foi com relação à falta de incentivo dos professores (46), seguido por falta de interesse dos próprios alunos (42), falta de tempo e falta de estrutura física da faculdade (32), falta de bolsas disponíveis para os projetos (19), bem como 5 alunos justificaram outros motivos.

A falta de incentivo dos professores, no entender dos sujeitos da pesquisa, compreende o aspecto que mais interfere na produção científica por parte dos alunos. Deste modo, para que ocorra o desenvolvimento de produção científica na Universidade é preciso o interesse e a iniciativa não só dos alunos, mas também dos professores, pois o professor deve oferecer a oportunidade para que o aluno possa participar de projetos. Sob este ponto de vista, Martins (2001) afirma que o professor atua como incentivador e promotor da investigação científica, tendo o papel de orientar o trabalho do aluno. Ele precisa explicar aos alunos como 
elaborar um projeto, desde sua iniciação e organização, desenvolvimento e execução, até a finalização ou conclusão.

Loureiro (1999), em seu estudo realizado com os egressos dos cursos de licenciatura da UFG, verificou que durante o período de graduação não houve um trabalho pedagógico com os acadêmicos, no que diz respeito à realização e publicação de trabalhos científicos. Essa situação, no entender da autora, é encontrada nos cursos de licenciatura, nos quais predomina a idéia de que os alunos devem assimilar o conhecimento, ao invés de produzi-lo. Não se utiliza a produção de trabalhos acadêmicos como estratégia no processo de ensino-aprendizagem.

Alguns alunos não têm conhecimento do que se passa na própria Universidade, ficando indiferente aos projetos de pesquisa e extensão que são realizados continuamente pela instituição e se privam de vivenciar tais experiências durante seu processo de formação no período de graduação. Juntamente com a falta de informação destacada acima, o próprio aluno não tem conhecimento do que isto é, e da importância de publicar trabalhos científicos. Este aspecto é ressaltado por um dos sujeitos (D2), ao relatar que a falta de participação pode ser devido à desinformação quanto à relevância dessas publicações para sua vida acadêmica e profissional.

Com relação à afirmação do sujeito citado, entendemos que os professores devem, em sala de aula, promover reflexões para que o aluno tenha conhecimento do que é produção científica e da importância disso em sua formação. No entender de Paiva e Taffarel (2001), a pesquisa científica deve ser reconhecida e realizada de forma que todas as disciplinas se constituam como produtoras do saber aprofundado e sistematizado. Com base neste argumento, a pesquisa passa, então, a ser entendida enquanto prática social, que se constitui também na relação das práticas pedagógicas.

Deste modo, é preciso que os alunos tenham a possibilidade de desenvolverem atividades de pesquisa na própria sala de aula, nas disciplinas oferecidas pelo curso de graduação, principalmente naquelas disciplinas específicas que trabalham metodologia científica, a fim de se elaborar propostas pedagógicas que envolvam todos os universitários. Bridi (2004, p. 74) ressalta que "para alguns professores, a introdução à pesquisa começa na graduação, na sala de aula, quando o professor desperta o interesse do aluno em aprofundar seus estudos na área de sua disciplina”.

Entendemos que a produção científica é algo fundamental e de grande importância na formação profissional, seja de Educação Física, como em qualquer outro curso. E esta relevância aparece em nossa pesquisa a partir da concepção dos alunos-sujeitos, quando 
abordam a importância da produção científica durante a graduação. Podemos verificar que esta questão é mencionada por quase todos os alunos, 105, e apenas uma pequena parcela, 6 , considera não ser importante. Este dado contradiz a afirmação do sujeito D2 de que uma possível causa da não publicação por parte dos alunos seja o desconhecimento da relevância disso para seus currículos. Pelo menos em seus discursos, esta conscientização parece presente entre a grande maioria dos acadêmicos.

Neste sentido, de acordo com Demo (2005), a pesquisa científica, entendida como princípio científico e educativo, é a maneira do aluno saber fazer, como também de refazer seu conhecimento, e assim, educar. Desta forma, ressalta-se o desafio do questionamento na busca da inovação. O questionamento reconstruído começa ao saber procurar e questionar. $\mathrm{O}$ aluno envolvido com pesquisa será motivado a tomar iniciativa, a apreciar leitura e biblioteca, a buscar dados e a encontrar fontes, a manejar conhecimento disponível. Ele exercita, pois, o questionamento sistemático, cultivando em si a criatividade e, deste modo, aprende a duvidar, a perguntar e a querer saber mais.

A pesquisa acadêmica pode ser considerada como uma atividade pedagógica que tem o intuito de despertar o espírito de busca intelectual de forma autônoma. Diante disso, é necessário que se aprendam as formas de problematizar, solucionar problemas, indicar respostas adequadas, e outros. Portanto, a pesquisa acadêmica é, antes de tudo, exercício, preparação (SANTOS, 2004).

Entretanto, com relação aos alunos matriculados no curso que possuem publicação, constamos que a maioria, numericamente 100, afirmou não possuir nenhuma publicação de trabalho científico durante a graduação. Chamou nossa atenção o pequeno número de acadêmicos que já publicaram, representado por apenas 11 sujeitos.

Este dado, coletado diretamente com os alunos do curso de Educação Física do CAJ/UFG, apresenta-se de forma alarmante, pois pudemos constatar que o número de alunos que possui contato direto e/ou indireto com produção científica em seu processo de formação profissional, durante a graduação, é muito restrito (equivale a $10 \%$ dos discentes em fase de formação). ${ }^{2}$ Neste sentido, Nascimento $(1999$, p.64) afirma que "o incremento de atividade de pesquisa para a formação de uma mentalidade científica justifica-se a partir das evidências encontradas que indicam uma pequena realização de atividades desta natureza na formação inicial".

Ao término da compilação dos trabalhos publicados pelos nossos sujeitos e análise destes dados, chamou nossa atenção o número reduzido. Recolhemos um total de 25 trabalhos

\footnotetext{
${ }^{2}$ Ressaltamos que estes dados são referentes ao ano letivo de 2006, quando a pesquisa foi realizada.
} 
que foram publicados entre o período de 2003 a 2006. Averiguamos que no ano de 2003, nenhum deles publicou; no ano de 2004, 12 trabalhos foram publicados; no ano de 2005 foram encontrados 9 trabalhos; e no ano de 2006, até o momento da coleta de dados da pesquisa (final do mês de junho), apenas 4 trabalhos tinham sido publicados.

Ao analisarmos a origem dos trabalhos publicados, preocupamo-nos em verificar a partir de que atividade eles surgiram, se do ensino, da pesquisa ou da extensão. Verificamos que 14 trabalhos publicados são frutos de projetos de extensão, 8 de projetos de pesquisa, apenas 1 do ensino, e 2 trabalhos são de outras áreas, um da Geografia e o outro da Biologia ${ }^{3}$. No entender de Paiva e Taffarel (2001), é preciso que as disciplinas dos cursos de graduação em Educação Física e Esportes superem suas formas fragmentadas e o modo pelo qual são expostas nos currículos, bem como devem rever o trato com o conhecimento que se estabelece no processo de trabalho pedagógico. Por isso, as produções científicas devem ser práticas constantes, que devem ser entendidas como um princípio educativo que orienta a formação dos profissionais da área.

\section{Algumas Considerações sobre a Pesquisa}

Foi possível perceber, a partir das informações encontradas na realidade investigada, que a produção científica por parte dos acadêmicos de Educação Física ainda é restrita e origina-se, predominantemente, das experiências em projetos de extensão, seguidas pelas situações de pesquisa e, em grau que podemos considerar insuficiente, pelo ensino, considerando-se a quantidade de disciplinas cursadas.

A justificativa para esta situação, a partir da opinião dos sujeitos, é de que há pouco incentivo por parte dos professores, existe a falta de interesse dos próprios alunos, a falta de tempo e precariedade de estrutura física da faculdade dificulta este processo, e ainda há poucas bolsas disponíveis para os projetos.

A produção científica na licenciatura é um ponto que requer especial atenção, pois pode contribuir em grande escala na formação do professor pesquisador, que investiga sua prática e a refaz, a partir de suas necessidades e das condições de seus alunos e do seu local de trabalho.

\footnotetext{
${ }^{3}$ Estes trabalhos de outras áreas foram mencionados por dois sujeitos que cursaram Geografia e Biologia, e foram publicados enquanto eram alunos nos cursos citados.
} 


\section{Referências Bibliográficas}

ARAGÃO, Marta Genú Soares et al. Projeto político pedagógico para o curso de Educação Física: caminhos percorridos. In: Anais do XI Congresso Brasileiro de Ciências do Esporte. Florianópolis - SC, 1999.

BRIDI, Jamile Cristina Ajub. A iniciação científica na formação do universitário. Dissertação de Mestrado (Educação). Faculdade de Educação, UNICAMP. Campinas, SP: UNICAMP, 2004.

CERVO, Amado Luiz; BERVIAN, Pedro Alcino. Metodologia científica. São Paulo: Makron Books, 1996.

COELHO, Ildeu Moreira. Formação do educador: dever do estado, tarefa da universidade. In: BICUDO, Maria Aparecida Viggini; SILVA JÚNIOR, Celestino Alves da (Orgs.). Formação do educador: dever do estado, tarefa da universidade. São Paulo: Editora da Universidade Estadual Paulista, 1996. p. 17 a 43.

DEMO, Pedro. Educar pela pesquisa. Campinas, SP: Autores Associados, 2005.

FÁVERO, Maria de Lourdes de Albuquerque. Produção e apropriação do conhecimento da universidade. In: MOREIRA, Antônio Flávio B. (Org.). Conhecimento educacional e formação do professor: questões atuais. São Paulo, SP: Papirus, 1994. p. 53 a 70.

FERRAZ, Leila Nívea Bruzzi. Formação e profissão: a postura investigativa e o olhar questionador na atuação do professor. Revista Movimento: Revista da Faculdade de Educação da Universidade Federal Fluminense. Niterói, RJ: PP \& A, nº 2, setembro, 2003. p. 67 a 79.

KRUG, Dircema Franceschelto. A formação de profissionais em Educação Física. In: Anais do XI Congresso Brasileiro de Ciências do Esporte. Florianópolis-SC, 1999.

LAKATOS, Eva Maria; MARCONI, Marina de Andrade. Técnicas de pesquisa. São Paulo: Atlas, 1996.

LOUREIRO, Walderês Nunes. Formação e profissionalização docente. Goiânia: UFG, 1999.

LUDKE, Menga; ANDRÉ, Marli E. D. A. Pesquisa em educação: abordagens qualitativas. São Paulo: EPU, 1986.

MARTINS, Jorge Santos. O trabalho com projetos de pesquisa: do ensino fundamental ao ensino médio. Campinas, SP: Papirus, 2001.

PAIVA, Andréia Carla de; TAFFAREL, Celi Neuza Zulke. Profissionais da educação física e esportes: formação e prática - uma análise da produção acadêmica de 1996 a 2001. In: Anais do XII Congresso Brasileiro de Ciências do Esporte. Caxambu, MG, 2001. CD-ROM

TRIVIÑOS, Augusto Nibaldo Silva. Introdução à pesquisa em ciências sociais: a pesquisa qualitativa em educação. São Paulo: Atlas, 1996. 
SANTOS, Antônio Raimundo dos. Metodologia científica: a construção do conhecimento. Rio de Janeiro: DP \& A, 2004.

VASCONCELOS, Maria Lúcia Marcondes Carvalho. A formação do professor de $3^{\circ}$ grau. São Paulo: Pioneira, 1996. 